\title{
Translation professions involving mental capacity to learn lexical, structural, semantic, stylistic, pragmatic
}

\author{
Anna Zavolzi ${ }^{1}$
}

\section{ARTICLE INFO}

Received: 27 November 2020

Revised: 18 December 2020

Accepted: 9 January 2021

\section{KEYWORDS}

lexical,

linguistic,

pragmatic,

semantic,

stylistic.

\begin{abstract}
Translation is a profession which does not require much physical ability. Translation mostly involves mental capacity to learn lexical, structural, semantic, stylistic, pragmatic, and, in a word, linguistic and to some extent, extra-linguistic aspects of another language, learning to use them practically to produce target texts acceptable in that language. It can be concluded that blind and visually impaired individuals can become translators due to the non-physical nature of this work. Thus, translation is one of the professions suggested by the researcher to blind and visually impaired individuals to earn their living. It should be kept in mind that translation has specific aspects which necessitate visual ability. All texts may have non-lexical elements bearing semantic values, such as pictures, figures, tables and diagrams. Some words and sentences may be bold or italicized or may be written in a color different from the rest of the text. Different sentences might be located in different places on the page for some purposes. All these issues can be problematic for a translator poor in vision.
\end{abstract}

Copyright (C) 2021 by The author(s). This is an open access article distributed under the terms of the Creative Commons Attribution (CC BY 4.0), which permits unrestricted use, distribution, and reproduction in any medium, as long as the original authors and source are cited. No permission is required from the authors or the publishers.

\section{Correspondence:}

3 Zavolzi, A.

亚 New York, NY 10003, United States, Phone: +1 212-998-1212

$\checkmark$ zavolzi.anna@nyu.edu 


\section{INTRODUCTION}

Mobility and independence are significant issues for those who are blind and visually impaired. While blind people can and do live productive lives, as well as receive full education, there are still some areas where greater independence could be achieved [1]. The progress of the modern world offers a better world with more suitable living and working conditions for people suffering from vision-related problems. A blind and low vision individuals are successfully employed at every occupational level, for example, as scientists, engineers, secretaries, and teachers, managers of businesses, laborers, and household workers.

In addition to blind and visually impaired translators, there is another group of individuals who are similar to this group in some respects. These individuals, distributed all around the world, are known as deaf-blind individuals. A basic and concise definition of deaf-blindness is "a concomitant loss of sight and hearing that is severe enough to limit a person's ability to conduct many functions of daily life. People who are deaf-blind may be completely deaf and blind, or they may have some usable hearing and vision, yet, it is the effects of a dual sensory loss that combine to create a unique circumstance. Today, people who are deaf-blind are no longer sheltered by their families. They live in the communities of their choice and are employed in every possible sector of the economy. Many individuals who are deaf-blind are teachers, program administrators, and businessmen and women" [2].

Loss of appropriate level of vision can also affect other disabled individuals. Many dyslexics experience visual problems when reading, often in addition to their phonological ones. These visual symptoms probably result from slight unsteadiness of the eyes when they are trying to fixate on the letters being read. This, in turn, results from their inheriting a mild impairment of the magnocellular component of the visual system, which plays an important role in controlling eye movements because it provides the major input to the ocular motor areas of the brain, such as the posterior parietal cortex, cerebellum and superior colliculus. This slight magnocellular impairment affects particularly the most vulnerable ocular motor control system, which is the control of the 'vergence' eye movements that point the eyes together to focus on near targets as when reading. Hence dyslexics' binocular vergence control tends to be unstable compared to normal readers. Because their eyes tend to wobble, letters may seem to move around, merge, flip and jump over each other. This is the reason why dyslexics tend to confuse the order of letters when attempting to read [3].
There are many challenges that come with being a visually impaired or blind person. For those who have congenital blindness or blindness from a very young age, it can be very difficult to imagine objects and scenery, such as a sunset, or even a dog [4]. On the other hand, reading the ST and writing its translation on paper or on a computer, using the necessary instruments for the task of translation such as dictionaries, encyclopedias, Internet, etc., sending the translated text to the client either physically or virtually through e-mail, are some of the challenges facing blind and visually impaired translators. The need for visual ability is even more noticeable in oral translation (interpretation). Oral translation, by its nature, has specific characteristics including gestures and body language, facial expressions, eye contact, speaker's clothing, his/her sitting or standing position. All are meaningful and should be taken into consideration during the translation process. Blind and visually impaired translators may encounter numerous difficulties reflecting such meaningful elements in their translations.

In addition to these challenges, lack of appropriate level of vision may influence the process of learning translation skills and the competencies of students who study such a major. Learning related vision problems are deficits in visual efficiency and visual information processing that can interfere with the ability to perform to one's full potential. Visual efficiency problems include reduced visual acuity, uncorrected refractive error, ocular motility and/or alignment problem(s), dysfunction of accommodation, and vergence control systems. Visual information processing problems include delays or deficits in visual spatial orientation, visual analysis skills, visual integration skills [5].

Although there are many challenges for translators suffering from any visual impairment, the modern world and its progress have solved many of their problems. Numerous writing systems such as Braille and Moon, various software designed to make computers accessible, including screen-readers, various computerized dictionaries and encyclopedias, numerous organizations attempting to provide several instruments and technologies for such translators, etc. have facilitated the process of translation for blind and visually impaired translators to a large extent. With the rise of various support-based organizations, more visually impaired people have been given the opportunity to receive an education as well as training with various aids [6].

\section{MATERIALS AND METHODS}

In order to prepare this paper, the researcher went through four steps as follows Step 1: The researcher gathered a large amount 
of information with both general and particular aspects related to the main topic of research. This information was gathered from a variety of books, essays, and websites.

Step 2: Two people who have had some experience in translation, either studying translation at the university or having some experience in this field or a combination of both, were selected as the subjects of the research. They were both either blind or visually impaired. After a short conversation between them and the researcher, they agreed to participate in the study. As the subjects lived in cities far from where the researcher was living, all the interview sessions were held via the internet, using Skype. The appropriate time for each interviewee's interview session was announced to him by the researcher, and at the time already determined, the interview started.

Step 3: After testing the recording devices and the interviewee's announcement that he was ready, the interview started. The interviewer welcomed the interviewee and thanked him for agreeing to participate in the interview. The interviewer reminded him that his answers should be based on his own personal knowledge and experiments, and asked him to feel free in answering the questions. It started with asking the interviewee to introduce himself and to provide a short biography about himself. The questions were asked one by one and the interviewee answered them carefully. At the end, the interviewer thanked the interviewee once again and the interviewing session was finished.

Step 4: The researcher wrote down the responses given by each subject for each question. He made a comparison between answers given and made a conclusion about a total response to each question. After making conclusions about each question separately, the researcher reviewed all the answers together and made conclusions as a whole about the major skills and abilities of blind and visually impaired translators so that he could answer the research questions one by one and either verify or reject its hypotheses.

As stated, the researcher conducted an interview session with each individual, during which he asked them six questions. The questions are listed in the last part of the paper. Subject A believes that blind and visually impaired translators are able to produce target texts with the same and even higher quality as sighted translators, depending on specific circumstances. For example, if the source text contains visual elements or if the translator has to navigate with the client, a blind or visually impaired translator may face some difficulties which are likely to decrease his/her translation speed.

Subject B believes that a text translated by an individual poor in vision can have the same quality as one translated by a sighted person but their speeds cannot be equal and a blind translator can't translate as fast as a sighted translator. However, he points out that there can be many variables affecting translation quality and vision isn't the only influential factor in this field. For example, he says that the difference between translation by a sighted translator and that of an individual poor in vision might be due to the difference in their knowledge and not because of the difference in their level of vision [7].

Both subjects believe that translators poor in vision can translate as well as and even better than sighted individuals, depending on the specific conditions provided for them. Less visual elements in the ST, navigation with the client, and the translator's knowledge are some such conditions. The researcher recommends clients keep these issues in mind when asking a blind translator to translate a text for them. He also suggests that various software and facilities should be designed to increase their speed of translation.

Subject A believes that there are more similarities rather than differences in their process of acquiring such skills and knowledge. He says both groups go to the same universities and institutes and study the same books. However, he believes that such individuals travel a pathway more difficult than sighted translators because they need to utilize specific tools such as recording devices, computers with particular programs, Braille and so on.

Subject B emphasizes that there are undoubtedly particular differences between their corresponding process of acquisition of such knowledge. He indicates two most important cases of such differences: it is easy for most students to find their university sources since most, and to some extent, all of their sources can be easily found in print format. Even those which are not published in print can be found on the Internet through a short search. This is not so easy for students suffering from visual problems. They are not able to read printed materials and the books they require are rarely and sometimes never published in a format accessible to them. Subject B added that such an opportunity is true for those students that study in Iran and not abroad [8].

To use dictionaries and to learn the spelling of words is another area in which he believes that there are differences between sighted people and those with poor vision. He says that although a dictionary is the main tool for any translator, most of the existing notable dictionaries are either produced only in print format or those produced in a computerized manner are not compatible with screen-readers designed for such people [9]. He also indicates that the spelling of words is one of the most challenging areas for blind and visually impaired students to learn. This may affect the quality of their translations.

Vol. 15 | No. 1 | 2021 | Pages: 18-27 
Both subjects pointed out that these individuals go through a more difficult process to become competent translators. They point mainly to their need to use specific recording and writing tools and books and resources in accessible formats. It is the duty of different organizations and institutions to provide these facilities for such people and also essential for academic and publication centers to disseminate various scientific and educational sources in formats which can be used by such students [10].

Major skills possessed by most individuals poor in vision which other people normally do not have, according to subject A, are computer skills. The most important of these skills is the skill known as touch-typing. Sighted individuals mostly use their vision while typing but individuals poor in vision keep the order of buttons on the keyboard in their minds and type without having to spend time finding a key on the keyboard. This can increase the speed of their typing, which can help them to translate faster.

Subject B regards oral translation as the area in which blind and visually impaired translators mostly surpass sighted translators. He gives two reasons for his claim: firstly, these translators can learn foreign words and keep them in their minds. Even if they face technical terms, they can ask a sighted person to record such words for them and subsequently learn them. Secondly, one of the major skills of blind and visually impaired people in which others are weaker is listening. It can help them perform oral translation more successfully than sighted people.

The researcher concludes from the responses that blind and visually impaired individuals possess three skills which can be helpful in the process of translation. They can type without need to look for the keys on the keyboard [11]. This may increase their speed of translation and can be regarded as a solution to the problem mentioned in the first question. It is recommended that clients use blind translators for the task of oral translation as a consequence of their higher listening capacity and their ability to keep a greater amount of input in their minds.

Subject A divides the necessary instruments and technologies of such translators into hardware and software. He regards the most important tool of these individuals to be a computer and a scanner both of top quality. Major software mentioned by him are screen-readers like JAWS and NVDA, and some other important software such as Easy-Transcribe for converting audio files into text ones. Mr. Choobiny considers on-line dictionaries, some computerized accessible dictionaries, and Google-Translate as the first and most useful instruments and technologies utilized by these translators.
The researcher concludes that computers and scanners are the most significant instruments utilized by these translators. They use computers with particular software and screen-readers installed on them and scanners to scan printed materials and convert them into accessible formats. Both these instruments are essential for such translators, since they need to read the source text for the purpose of translation and also to review the receptor text and revise it if required [12].

In subject A's view, quality is the first and most important criterion for clients. They pay no attention to the visual level of translators, and, in fact, they make no distinction between blind and visually impaired translators and sighted ones. He even mentions some instances where a client asked a sighted person to translate a text for him but after receiving the translation and checking it, he has changed his mind and returned to the subject to translate the text.

Mr. Choobiny answered that first most people do not view blind and visually impaired translators in the same manner as sighted ones. However after a period of time when the blind or visually impaired translator proves his/her abilities and competencies, most people change their viewpoint and trust his/her capacity to translate. He uses himself as an example and says that many people are at first surprised to see that he is able to translate, but after a period of time, they recognize that he translates better and faster than many sighted translators.

The investigator believes that many attempts should be made to changes people's views about the skills and abilities of translators poor in vision. The government and other officials must adapt numerous policies and take a variety of actions to make people, and especially employers, familiar with the abilities of these translators and accept them like all other translators.

Subject A believes that blind and visually impaired translators can take part in the process of oral translation as long as visual elements carrying semantic value are not involved. Subject B believes that oral translation is the field in which a blind or visually impaired translator can surpass a sighted translator because of his/her superiority in listening. He says that if there were two translators, one sighted and another one blind or visually impaired, both with the same level of linguistic competency, the blind or visually impaired translator will give a better performance in oral translation. The reason he gives is that visual elements in the environment may distract the sighted translator; something which would not happen for the translator poor in vision [13].

Both the subjects are sure that blind and visually impaired individuals can participate in the process of oral translation. They both believe that many of the difficulties that these

Zavolzi, A. (2021). Translation professions involving mental capacity to learn lexical, structural, semantic, stylistic, pragmatic. Applied Translation, 15(1), 18-27. https://doi.org/10.51708/apptrans.v15n1.1358 
people may encounter in written translation do not exist in oral translation. They even claim that this is an area where blind and visually impaired individuals can perform better than sighted people.

\section{RESULTS AND DISCUSSIONS}

The researcher suggests that translators poor in vision, before accepting any material to translate, would be best to ask the client to give a brief explanation about the location of texts on the page and the visual elements existing in the material. Being aware of the location of texts on the page can help prevent producing a low-quality TT due to missing any significant point in the ST. The researcher believes that it is helpful for such translators to receive some information about the various visual elements of the text and their content. Blind and visually impaired translators can ask the client to write down on a separate sheet or record on a tape or CD a brief explanation of the pictures, tables, figures, etc. accompanying the source text.

The researcher also suggests that blind and visually impaired translators, providing that they receive no explication regarding such elements, would be best to refuse to translate such material. Ignoring the visual elements may lead to missing significant points and producing low-quality and unacceptable target texts. Such a phenomenon may have more harmful consequences and cause other clients to not to trust him/her with the task of translation [14].

Most blind and visually impaired individuals prefer to translate with a computer rather than on paper. Translating on paper has numerous difficulties for both blind translators and for visually impaired ones. People who have limited vision and are not completely blind may be able to read printed texts and even write such materials, however, their reading speed is less than sighted individuals. In order to read each word and line, they have to make more effort, which may cause them to get tired sooner. Their ability to read may be limited to specific circumstances, including the particular amount of light, certain paper types with specific color and contrast, and many other factors. Such individuals are likely to miss some points included in the text. The researcher believes that it is fair and helpful to have documents with more appropriate fonts and darker words typed on white sheets translated by translators poor in vision, and other documents lacking such characteristics translated by sighted individuals. Blind people can use such systems as Braille to read texts on paper. However, using these systems in the task of translation has more severe challenges. Very rarely are materials produced in such formats. Even if material is produced in, for example, Braille format, the blind translator cannot deliver his/her rendering in Braille since most sighted people cannot use it. It is also impossible to send a Braille text via e-mail. It can be thus concluded that it is more reasonable to use a computer for the task of translation [15].

The modern world and its progress has made the computer an accessible tool for blind and visually impaired translators. Visually impaired individuals can use a variety of software to adjust different parts of their screen in a way suitable for them. Blind individuals can also use various screen-readers designed to make computers accessible for them. The researcher believes that blind and visually impaired translators, like other translators, should recognize the prominent status of the computer in the world of translation. He indicates that it's a crucial duty of translation teachers and principals to make such individuals aware of this and help them to add computer skills to their other skills and abilities.

Most blind and visually impaired translators also use scanners in order to scan printed materials so that they can convert them into accessible formats and read their content. This device is mostly utilized with a famous software named Kurzweil. This software converts the scanned material into a format that the blind or visually impaired person can read using his/her screenreader [16]. However, the problem of supporting the Persian language does exist for scanners. No scanner currently exists that is capable of scanning Persian documents. The researcher indicates that individuals suffering from visual problems must recognize the significant connection between scanners and Kurzweil and the importance of their combined use to be able to translate printed materials.

Nobody can deny the high significance of dictionaries and encyclopedias in the process of translation. Use of appropriate bilingual and monolingual dictionaries and adapting a correct strategy to utilize them can to a large extent guarantee a successful translation. Like other translators, blind and visually impaired people need different kinds of both bilingual and monolingual dictionaries and encyclopedias. The researcher offers some suggestions for blind and visually impaired translators in this area. He believes that all publication centers should produce dictionaries and encyclopedias in such accessible formats as Braille and Moon. He also suggests that blind and visually impaired individuals can establish a group in a company or institution whose role is either to ask other companies to produce such data sources in accessible formats or they themselves attempt to produce such accessible data sources. A better suggestion can also be to design software capable of converting any computerized dictionary or encyclopedia into an accessible format and permitting these individuals to perform the task of converting by themselves.

The following four cases are the major areas in which blind and visually impaired translators can surpass sighted ones Listening: It is common knowledge that most people poor in

Vol. 15 | No. 1 | 2021 | Pages: 18-27 
vision try to utilize their auditory senses so that their ears do what their eyes are unable to do. Thus, we can conclude that people who suffer from visual deficiencies possess a better listening ability. Higher listening ability can be very helpful for blind and visually impaired translators. It can help them to read their documents with their screen-readers more rapidly, and therefore to translate the text more quickly and deliver it to the client earlier than a sighted person. The area in which listening plays a very significant role is oral translation. Reading these sentences, it can be concluded that blind and visually impaired translators can use their stronger listening competencies to surpass sighted translators, particularly in the case of oral translation [17].

Faster Typing: Blind and visually impaired individuals usually type faster than others. This is so because they spend no time finding the button which they're going to press on the keyboard. They keep in their mind the location of each key and the arrangement of buttons on the keyboard. Sighted people use their eyesight to find a button on the keyboard. This would decrease the speed of their typing. We thus conclude that blind and visually impaired translators might be able to type faster than sighted translators [18].

Better Presence of Mind: As blind and visually impaired translators are not able to see the texts, they have to practice to keep more information in their minds. This is true for both written translation and more significantly for oral translation. In the case of written translation, if a blind or visually impaired translator keeps a small amount of the source text in his mind, he will be forced to repeatedly navigate the open windows of source and target text. This would be too boring and waste his time. However, blind and visually impaired translators, due to their conditions, try to keep large amounts of the source text's information in their minds. This would contribute to them translating more rapidly. Such a capacity is more helpful in oral translation where the information received is temporary and disappears as soon as it is spoken. Higher presence of mind can help the blind or visually impaired translators to translate faster than sighted translators.

Freedom from Presuppositions: A sighted person may start translating with a variety of backgrounds in his/her mind. These backgrounds may include different pictures, locations, scenes, people, and other phenomena that (s)he has seen during his/her life. These visual elements may affect his/her translation. They may distract the translator or create particular attitudes in his/her mind which cause him/her to translate in a specific manner. A blind translator is free from such presuppositions and his/her rendering can be a regarded as a 'pure' text [19].
The researcher concludes from the above paragraphs that blind and visually impaired individuals can perform oral translation better than sighted ones. Superior capacity of listening and better presence of mind, facilitating the ability to keep more information in mind are helpful in this type of translation. So, he suggests that blind and visually impaired translators should be preferred for the task of oral translation.

Another skill possessed by translators poor in vision, assumed by the researcher, is that their pronunciation is more similar to native speakers. They use various screen-readers. The eloquence of these screen-readers is mostly native English. Thus, they are more familiar with the correct pronunciation of English terms. The researcher recommends ESL students to follow their pronunciations, as they pronounce words in a way more similar to native speakers.

As stated before, translation is a task which is influenced by numerous factors. Such issues as age, sex, social class, educational background, the translator's financial and economical status, the amount of his payment, the deadline given for the delivery of a translation, his emotional condition, all influence the quality of his translation. The next issue is to discuss whether the changes that occurred in a translated text are due to the visual level of its translator or any of these factors.

In addition to vision, the deficiencies in the other parts of body can influence the quality of a translated text. The other task is to identify any other deficiency which may have more severe effects on translation quality.

As stated before, blind and visually impaired individuals are distributed all around the world. In each country there are either a large majority or a small minority of such people. Translation is the profession of many of these people. Thus, the living and working conditions of translators poor in vision are not the same all around the world. The other issue to be discussed is a comparison between the living and working conditions of blind and visually impaired translators in Iran and those living in some other modern countries like the U.S. and Canada [20].

Dictionaries and encyclopedias are among the first and most important instruments used by a translator. In fact, no translation task can be done without using such data sources. In the past, translators had to use paper dictionaries and encyclopedias in order to find a word and its meanings. This was exhausting and very time-consuming. Today translators can find various meanings of a word very rapidly and without spending a large amount of energy by using computerized and on-line dictionaries and encyclopedias. This fact is also true for translators suffering from visual problems. There will be a 
comparison between the way blind and visually impaired translators used such data sources and the way they use them in the modern world.

As stated before, oral translation is one of the areas in which blind and visually impaired translators can perform better than sighted translators and may even surpass them. In our country, a number of conferences, festivals, and interviews have been held where the task of oral translation was done by a blind or visually impaired individual. Make a list of such opportunities and compare them with those done by sighted translators. The approach to the nature of linguistic meaning and word equivalents - classifies translations into three groups:

1) intralingual translation, or rewording: an interpretation of verbal signs using other signs in the same language.

2) interlingual translation, or actual translation: an interpretation of verbal signs using another language.

3) intersemiotic translation, or transmutation: an interpretation of verbal signs using a nonverbal sign system.

Interlingual translation is done for example when someone wants to say something in another way, either in the form of an expression or text in the same language to explain or clarify something that has been explained or written. Intersemiotic translation is done when a written text is translated, for example, into music, films or paintings. Interlingual translation is a traditional translation that is the focus of studies in translation studies. There are at least two main objectives of this translation study, including:

1) to describe the phenomenon of translation and translation as they are real in the world of our experience.

2) to establish general principles using explainable and predictable phenomena.

It makes a very important statement that 'all cognitive experiences and their classifications can be conveyed in any language.' He cites British English concepts such as the National Health Service, public-private partnership and congestion charging, or in the United States. , Ivy League university, Homeland Security and speed dating can also be expressed in various ways in the target language.

The key issue raised in particular concerns linguistic meaning and word equivalents. The approach taken is still heavily following the Saussure concept, namely the signifier (spoken and written signs) and signified (the concept of signs). Signifier and signified form linguistic signs, but they are either like or not motivated. As exemplified, the word cheese in English is an acoustic signifier which shows the concept of food made from compressed milk starch (signified).
Interlingual translation involves replacing messages in one language not to separate code units, but for the entire message in another language. Translators recode and transfer messages received from other sources. Therefore, translation includes two equivalent messages in two different codes.

For the equivalent message in TS and TT, the units of code will be different as long as the codes are in two different sign systems (different languages). From a linguistic and semiotic standpoint, Jakobson discusses the problem of equivalence with a definition that has now become famous: equivalence in difference is a central problem of language and is a very important linguistic consideration. The problem of meaning and equivalence focuses on differences in language structure and terminology, not on the inability of a language to carry messages that have been written in other verbal languages.

The interlinguistic distinction surrounds the grammatical and lexical forms: languages differ essentially in what has to be conveyed and not in what can be conveyed. Examples of differences are easy to find and they occur in:

1) gender level: eg house is feminine in Roman languages, neutral in German and English; honey is masculine in French, German and Italian, feminine in Spanish and neutral in English.

2) Aspect level: in Russian the verb morphology varies according to whether the action in question has been carried out or not.

3) semantic field level: children in English in the statement 'I've got two children' is translated hijas in Spanish if the two children are meant to be girls.

The problems of meaning, equivalence, and translation skills became a continuous theme in translation studies in the 1960s and were handled by a new scientific approach by one of the most important figures in translation studies, namely Eugene Nida.

Eugene Nida and "The Science of Translation" Nida's theory of translation developed from her work experience from the 1940s onwards when she translated and organized the translation of the Bible. His theory is used in concrete form in his two major works (1) Toward a Science of Translating (1960), and (2) Theory and Practice of Translation [12]. Nida's translation approach then became more systematic after adopting 'theoretical concepts and semantic and pragmatic terminology, and Chomsky's theory, namely Grammar for Generative Transformation.

Nida classified meaning into two parts, (1) linguistic meaning (to borrow elements from Chomsky's model); (2) referential meaning (denotative meaning - the meaning in the dictionary 
and the emotive meaning (connotative)). A series of techniques are adapted from various works in linguistic studies and are presented as an aid to the translator in determining the meaning of different linguistic elements. The techniques offered in determining referential meanings and emotive (connotative) meanings focus on analyzing word structures and distinguishing similar words in the associated lexical field. This includes ranking sequences that differentiate word strings according to their rank (for example, animal subordinates and hyponyms: cow, goat, cat, dog, etc.), and component analysis techniques (e.g. in identifying and distinguishing grade specific characteristics. related words. The results can be described visually to assist in making a comprehensive comparison. Nida (1964a: 84--5) exemplifies the delineation of relationship terms (grandmother, mother, cousin, etc.) by sex (male, female), generation (same, one, two, or more separate) and direct descendants (direct ancestor / descendant or not). The results are very useful for translators, especially in translating a language that has a different system of family ties.

Another technique initiated by Nida is semantic structure analys. He visually separates the different meanings of spirits ('demons', 'angels', 'gods', 'ghost', 'ethos', 'alcohol', etc.) according to their characteristics (human vs. non-human; good vs. bad, and others). The main idea of this analysis is that the meaning of a complex semantic term such as spirit (or another example bachelor's) varies widely and is more importantly 'conditioned' by the text. Spirit is not always associated with religious significance. The term Holy Spirit, its emotive and connotative values vary according to the target culture.

In general, component analysis techniques are intended as a way of clarifying ambiguity, avoiding obscurity and identifying cultural differences. All of this can provide a comparison of different languages and cultures. Chomsky's strong influence on the theory developed by Nida can be summarized as follows:

1) the structure-phrase rule derives a layer or inner structure

2) transformed by using the transformation principle connecting the structure layer to another structure layer (eg active to passive, to produce

3) a final outer structure, which is subject to phonological and morphemic rules.

The outer structure of the TS is analyzed into the basic elements of the inner structure which are then transferred to the translation process and then restructured semantically and stylistically into the outer structure of the TT. This three-level translation system (analysis, transfer, and restructuring) can be described as follows.
Nida and Taber's description of the process emphasizes the advantages of 'scientific' and 'practical' over any attempt to compile a truly comprehensive list of equivalents between the specific pairs of BS and BT systems. 'Core' is the key term in this model. Like the core sentences which are the basic structural elements of Chomsky's initial model. Thus, for Nida 'the nuclei are the basic structural elements and language constructs its detailed outer structure' (Nida and Taber 1969: 39). The cores are obtained from the outer structure of the TS by a process of reduction of the re-transformation (Nida 1964a: 63--69). This involves analysis using four types of functional class grammar generative transformations:

1) events (often but not always by verbs).

2) objects (often but not always by nouns).

3) abstract (quantity and quality, including adjectives).

4) relational (including gender, prepositions and conjunctions).

\section{CONCLUSION}

With regard to equivalents, it provides two basic orientations or types of equivalents, namely (1) formal equivalents, and (2) dynamic equivalents. The formal equivalent focuses its attention on the message itself, both form and content... that the message in the language of the recipient must match as closely as possible the different elements in the BS. The formal equivalents are rigorously oriented towards the TS structure, which exerts a strong influence on determining accuracy and correctness. Dynamic matching is based on the principle of equivalent effect, where the relationship between the recipient and the message is substantially the same as that between the original recipient and the message. Messages must be created to meet the linguistic needs of the recipient and cultural expectations and "lead to a complete reasonableness of expression". The purpose of this dynamic equivalent is like finding the natural equivalent that comes closest to the $\mathrm{BS}$ message.

They are used extensively in translator training, a combination of practical examples of linguistic meaning theory, and translation applications. It is to approach departs from ideas that had been coined by Nida. To avoid the similarity of terms, especially in SL and TL, Newmark uses the terms "semantic translation" and "communicative translation". The communicative translation tries to produce an impact for the reader as closely as possible so as to acquire authenticity for the reader [8].

Semantic translation attempts to translate as closely as possible the syntactic and semantic structure of BT, the contextual 
meaning of the original. This description of the communicative translation is similar to the dynamic equivalent suggested by Nida, while the semantic translation is the same as the formal equivalent. Newmark's definitions of these two types of translation reveal clear differences, as can be seen below. Several other writers who are closely related to Jakobson's ideas in particular are related to equivalent theory.

\section{Conflict of Interest Statement}

The authors declare no conflicts of interest related to the material presented in this article.

\section{REFERENCES}

[1] Al-Hadithy, T. M. (2015). The traditional vs. the modern translation classroom: A need for new directions in the UAE undergraduate translation programs. ProcediaSocial and Behavioral Sciences, 192, 180-187. https://doi.org/10.1016/j.sbspro.2015.06.026

[2] Birkan-Baydan, E., \& Karadağ, A. B. (2014). Literary translation workshop: Social constructivist approach classroom activities. Procedia-Social and Behavioral Sciences, 152, 984-988. https://doi.org/10.1016/j.sbspro.2014.09.354

[3] Calis, E., \& Dikilitas, K. (2012). The use of translation in EFL classes as L2 learning practice. Procedia-Social and Behavioral Sciences, 46, 5079-5084. https://doi.org/10.1016/j.sbspro.2012.06.389

[4] Çelik, P. G., \& Özcan, L. A. (2013). Determining proficiency level in foreign language teaching: the case of translation and interpretation students. Procedia-Social and Behavioral Sciences, 70, 288-304. https://doi.org/10.1016/j.sbspro.2013.01.067

[5] Chan, A. L. J. (2011). Information economics and the translation profession: an empirical investigation into translator certification and other signaling mechanisms in the translation marketplace. Lambert Academic Publishing.

[6] Chesterman, A. (2005). Where are we going?: future prospects in the translation profession. KääntäjäÖversättaren, 2005(6-7), 8-9. Lin, S., Chaiear, N., Khiewyoo, J., Wu, B., \& Johns, N. P. (2013). Preliminary psychometric properties of the Chinese version of the work-related quality of life scale-2 in the nursing profession. Safety and health at work, 4(1), 37-45. https://doi.org/10.5491/SHAW.2013.4.1.37

[7] Coban, F. (2015). Analysis and training of the required abilities and skills in translation in the light of translation models and general theories of translation studies. Procedia-Social and Behavioral Sciences, 197, 707-714. https://doi.org/10.1016/j.sbspro.2015.07.074
[8] Dejica-Cartis, D. (2012). Developing the Electronic Tools for Translators Syllabus at Politehnica University of Timisoara. Procedia-Social and Behavioral Sciences, 46, 3614-3618. https://doi.org/10.1016/j.sbspro.2012.06.115

[9] Di Michele, L., Thomson, K., McEntee, M., Kenny, B., \& Reed, W. (2020). Knowledge translation: radiographers compared to other healthcare professionals. Radiography. https://doi.org/10.1016/j.radi.2020.06.007

[10] Doherty, S. (2016). Translations| The Impact of Translation Technologies on the Process and Product of Translation. International Journal of Communication, 10, 23. Epstein, J., Osborne, R. H., Elsworth, G. R., Beaton, D. E., \& Guillemin, F. (2015). Cross-cultural adaptation of the Health Education Impact Questionnaire: experimental study showed expert committee, not backtranslation, added value. Journal of clinical epidemiology, 68(4), 360-369. https://doi.org/10.1016/j.jclinepi.2013.07.013

[11] Gavrilenko, N. N., \& Biryukova, Y. N. (2019). Forecasting the Translation Profession Development: Foresight Technology. Journal of History Culture and Art Research, 8(4), 123-134. https://doi.org/10.7596/taksad.v8i4.2365

[12] Go, K. J. (2015). 'By the work, one knows the workman': the practice and profession of the embryologist and its translation to quality in the embryology laboratory. Reproductive biomedicine online, 31(4), 449458. https://doi.org/10.1016/j.rbmo.2015.07.006

[13] Kania-Richmond, A., Menard, M. B., Barberree, B., \& Mohring, M. (2017). "Dancing on the edge of research"What is needed to build and sustain research capacity within the massage therapy profession? A formative evaluation. Journal of bodywork and movement therapies, 21(2), https://doi.org/10.1016/j.jbmt.2016.06.019

274-283.

[14] Kelly, L. G. (1995). History of translation. In Concise History of the Language Sciences (pp. 419-430). Pergamon. https://doi.org/10.1016/B978-0-08-042580$1.50065-9$

[15] Kettunen, J. (2017). Interlingual translation of the International Financial Reporting Standards as institutional work. Accounting, Organizations and Society, 56, 38-54. https://doi.org/10.1016/j.aos.2016.10.001

[16] Marchionni, N., Ferrucci, L., Baldasseroni, S., Fumagalli, S., Guralnik, J. M., Bonazinga, M., ... \& Masotti, G. (1997). Item re-scaling of an Italian version of the Sickness Impact Profile: effect of age and profession of the observers. Journal of clinical epidemiology, 50(2), 195-201. https://doi.org/10.1016/S0895-4356(96)00318-6

[17] Robson, K. (1991). On the arenas of accounting change: the process of translation. Accounting, Organizations and 
Society, 16(5-6), 547-570. https://doi.org/10.1016/03613682(91)90041-C

[18] Sha, B. L. (2011). Accredited vs. non-accredited: The polarization of practitioners in the public relations profession. Public Relations Review, 37(2), 121-128. https://doi.org/10.1016/j.pubrev.2011.02.003

[19] Sirisawasd, P., Chaiear, N., Johns, N. P., \& Khiewyoo, J. (2014). Validation of the thai version of a work-related quality of life scale in the nursing profession. Safety and health at work, 5(2), 80-85. https://doi.org/10.1016/j.shaw.2014.02.002

[20] Waldorff, S. B. (2013). Accounting for organizational innovations: Mobilizing institutional logics in translation. Scandinavian Journal of Management, 29(3), 219-234. https://doi.org/10.1016/j.scaman.2013.03.010 